\title{
Effect of Machine Parameters on Starting Transients of Grid Connected Induction Generators used in Wind Farms
}

\author{
Sudhir Sharma \\ Associate professor and Head, Department of \\ Electrical Engineering \\ DAV Institute of Engineering \& Technology, \\ Jalandhar, Punjab, INDIA
}

\author{
K.S. Sandhu \\ Professor and Head, Department of Electrical \\ Engineering \\ National Institute of Technology, Kurukshetra, \\ Haryana, INDIA
}

\begin{abstract}
Induction generators (IGs) are becoming important day by day in wind energy conversion. As such the numbers of IGs in a power system are increasing hence posing power quality problems. When large numbers of IGs are switched on or switched off from a circuit give rise to transients in the power system. In this paper authors tried to explore the effect of machine parameters on starting transients thereby making an effort to control these transients by controlling the machine parameters.
\end{abstract}

\section{Keywords}

Induction generators, power quality, wind generation, induction generator parameters.

\section{INTRODUCTION}

The use of induction generators is increasing with increasing demand of green energy. As IGs have robust construction, very less maintance, no requirement of synchronization making them a preferred choice. The biggest drawback of IG is its requirement of large reactive power as it can generate active power only. The demand of reactive power can be met either from grid or via capacitor bank. Hence when connected to grid these may draw heavy inrush current. Despite serious supply disturbance, an induction generator has been shown to be safe in operation when suitable protection measures have been taken. Comparing VAR requirements of the different generator types shows a significant difference, and may have a profound influence on the overall system performance [1]. The effects of starting on the electric oscillations of an autonomous induction generator and experimental results that explain and justify the need for a larger capacitor at the start are presented by Raul Rabinaici et al. Furthermore, experimental results about the influence of the series resistor and stator inductance were also shown by [2] \& [3]. The performance of the induction generator connected to a system was used to develop an understanding of the issues of voltage dip and harmonics. Additionally, some insights have been presented on sizing a reactive power device to address the voltage dip problem by some authors. Soft stating of induction generators was also discussed to minimize the starting transients [4].

In this paper an attempt is done to develop a SIMULINK model of GCIG and SEIG to see the effect of machine parameters and speed on the starting transients. This paper is divided into three sections in the first section the Simulink model with detailed system description are given. Second section shows the results and in last part discussion and recommendation are given.

\section{SYSTEM CONFIGURATION}

Two types of configurations / modes are studies in this paper i.e. grid connected and self excited mode. Induction machines of $160 \mathrm{~kW}$ rating are used for this study in grid connected and in SEIG operation mode. MATLAB/ SIMULINK models are developed for study of grid connected machines is shown in fig 1 and for self excited induction generator is shown in fig 2 . Effect of Rotor and stator resistance (Rr \& Rs), rotor and stator inductances ( $\mathrm{Lr} \& \mathrm{Ls})$ and mutual inductance (Lm) on starting transients are studied.

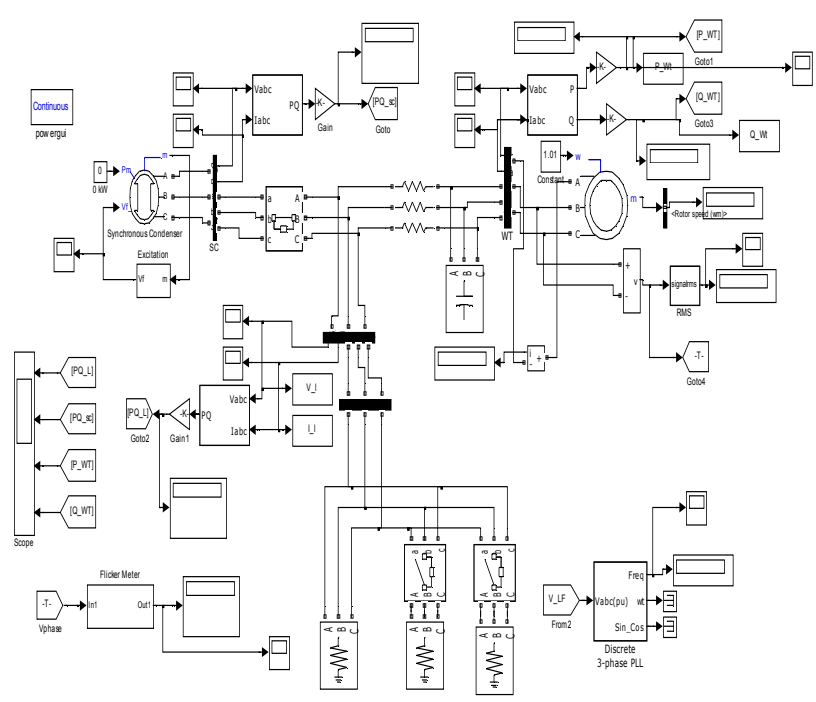

Figure 1 


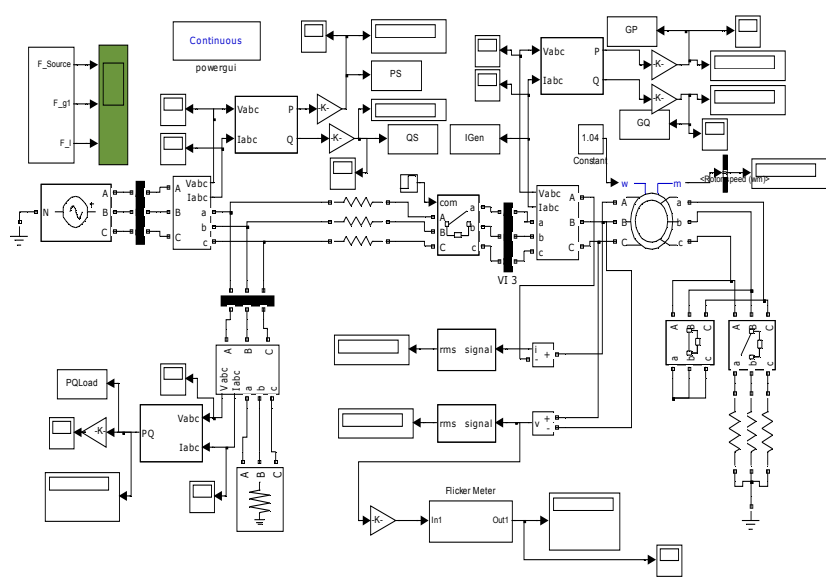

Figure 2

\section{SIMULATED RESULTS}

Fig 3 gives the variation in peak reactive power drawn by the induction generator at different values of rotor resistances. These effects are plotted at different values of speed to study the effect of wind speed also. Fig 4 shows the variation in peak reactive power w.r.t speed and rotor resistance.

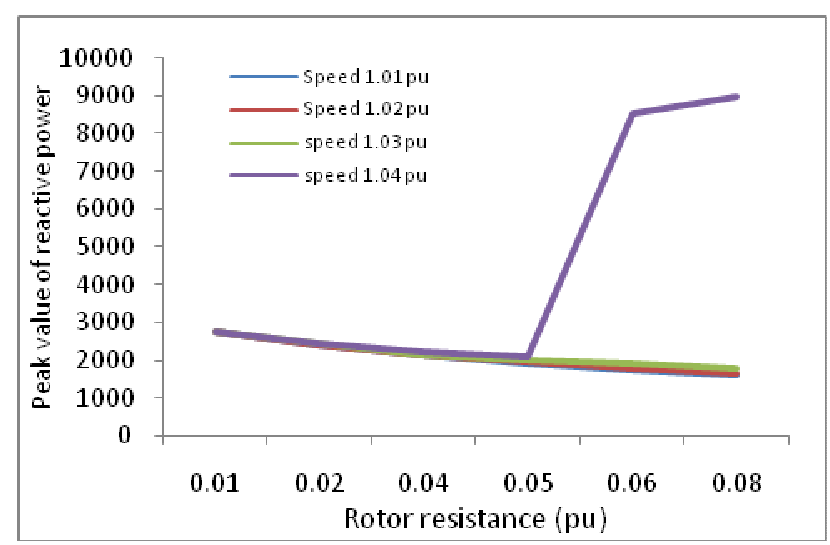

Figure 3

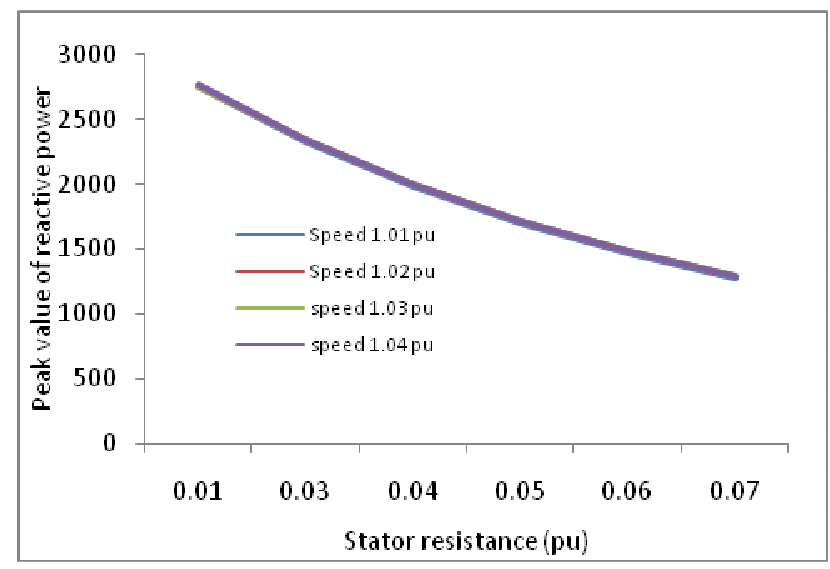

Figure 4

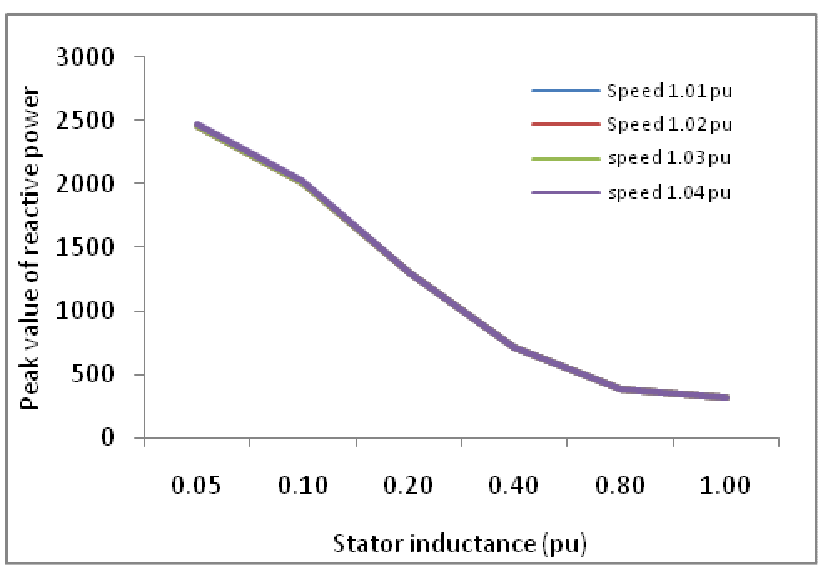

Figure 5

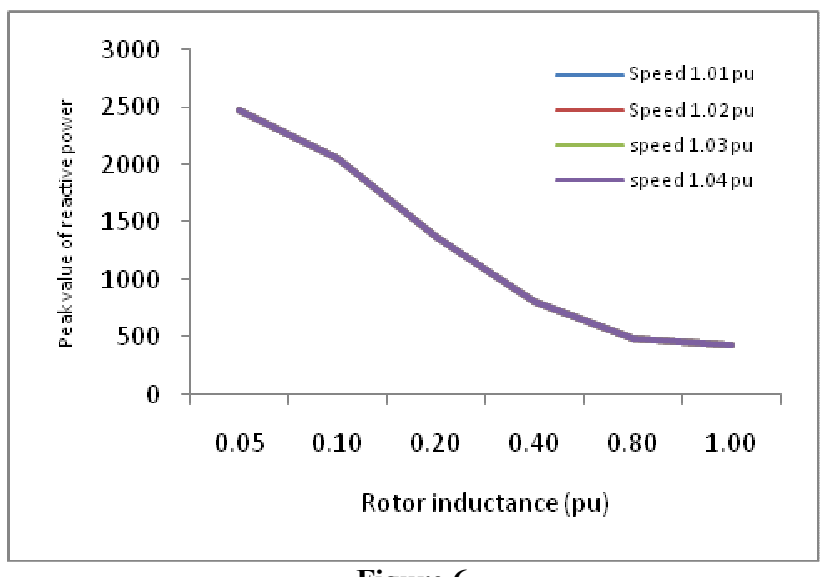

Figure 6

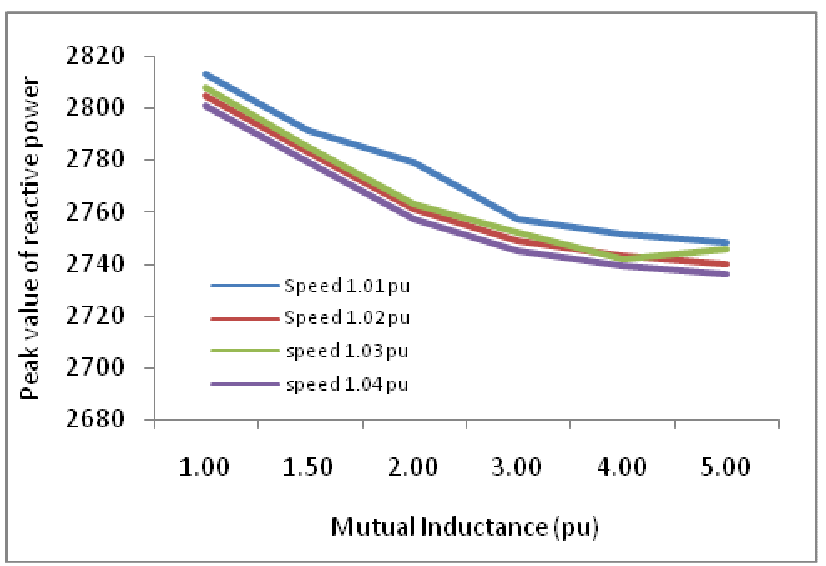

Figure 7

Fig 5 to 7 shows the variation in peak reactive power drawn by the IG during staring w.r.t. Ls, Lr and Lm at different values of operating speeds. 


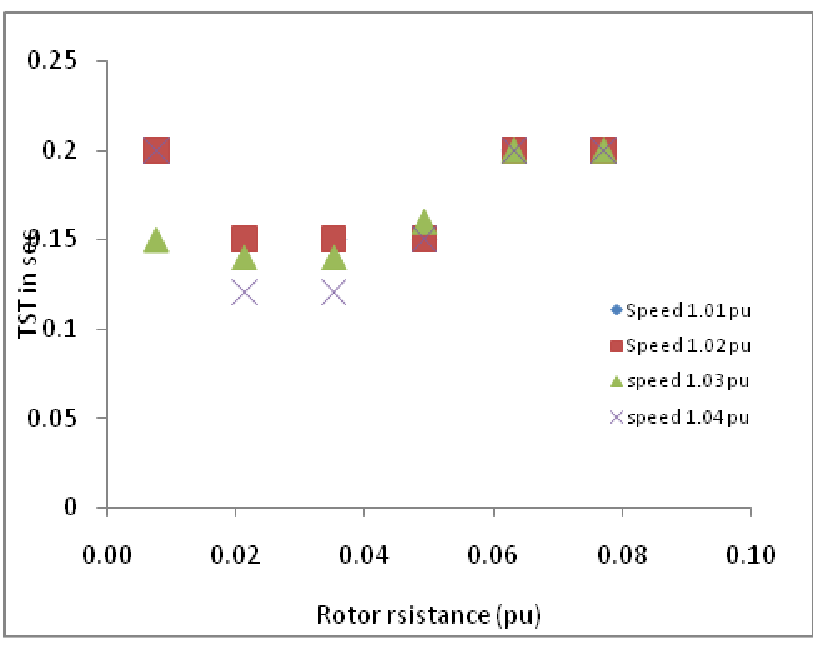

Figure 8

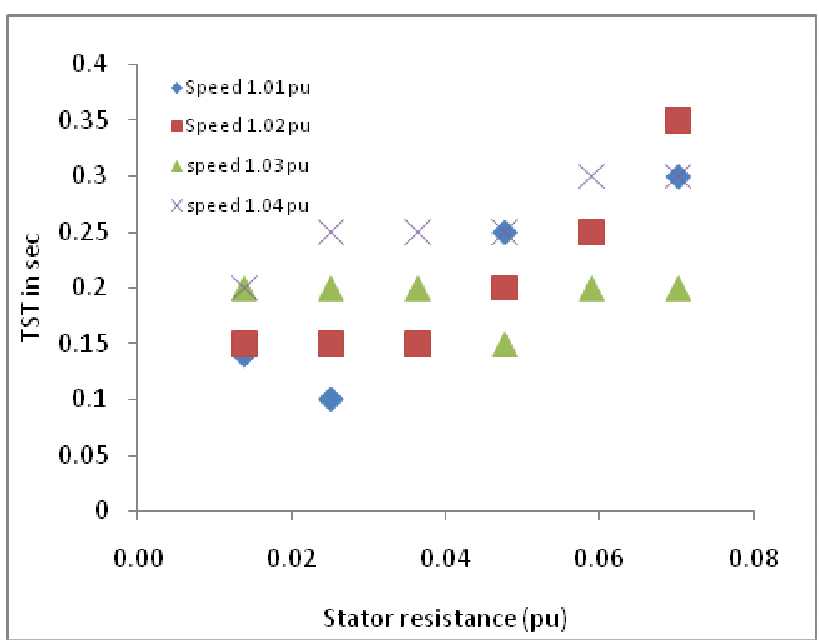

Figure 9

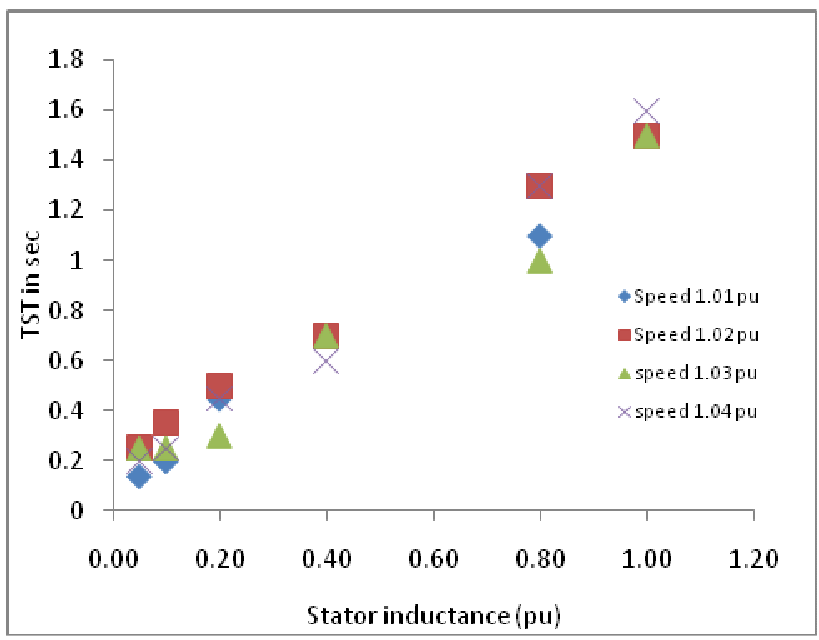

Figure 10

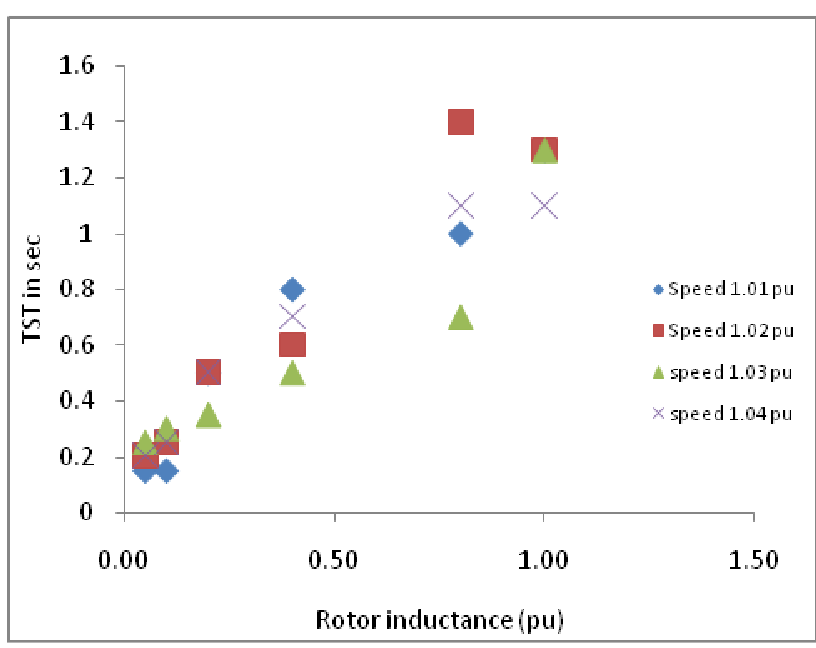

Figure 11

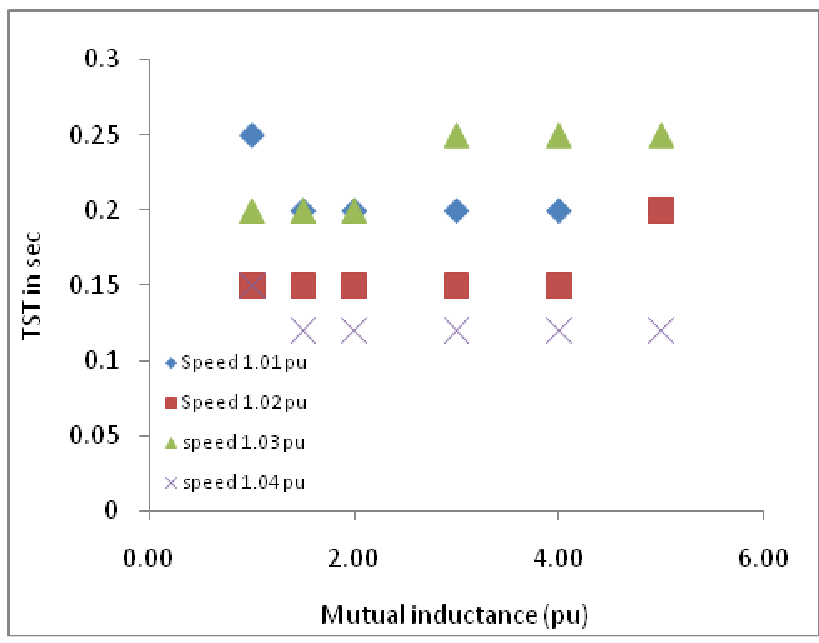

Figure 12

Fig 8 to 12 gives the variation in starting transient settling time w.r.t Rs, Ls, Lr and Lm at different values of slips.

\section{ANALYSIS OF RESULTS}

Large current is drawn by the induction machine at the time of starting due to large magnetizing current requirement of the machine. Hence to analyze the effect of machine parameters on peak reactive power drawn the graphs are drawn between machine parameters and peak reactive power. From analysis of results it is quite evident that increase in rotor resistance reduces the peak of starting transients but the machine becomes unstable at slip $1.04 \mathrm{pu}$ and rotor resistance beyond $0.05 \mathrm{pu}$. Change in slip does not show any significant effect on starting transients. Increase in stator resistance also reduces the starting transient. But stator inductance and rotor inductance shows significant reduction in starting transients as magnetizing current has direct relationship with stator and rotor inductance. Slip again has not shown any effect on starting transients. Increase in mutual inductance too reduces the starting transient but here the slops are different for differ slips. Only Stator resistance, stator inductance and rotor inductance affected the transient settling 
time. Transient settling time is shown increasing with increase in these parameters. This is due to the change in time constants with change in said parameters.

\section{CONCLUSION}

Form this study it may be concluded that by controlling the machine the starting transients and transient settling time can be controlled. Machine parameters which are found to be effective to control starting transients may also be decisive in deciding the switching sequences when large numbers of machines are operating in a wind farm. Further some optimizations techniques may be used for selecting the machine parameters resulting into power quality supply.

\section{REFERENCES}

[1] N P McCJuin, P N Williams, S Williamson "Transient electrical and mechanical behaviour of large induction generator installations".
[2] Raul Rabinaici and Natan Ben- Hail "Starting Oscillations of an Autonomous Induction Generator" IEEE Transactions on Magnetics. VOL 35, NO 5, September, 1999.

[3] Timothy W. Bartel "Operating Experience with an Induction Wind Generator on a $12.5 \mathrm{kV}$ Distribution System" 1-42441 002-9/07/\$25;00 @2007 IEEE

[4] G. Quinonez-Varela and A. Cruden "Modelling and validation of a squirrel cage induction generator wind turbine during connection to the local grid" IET General Transmission Distribution, 2008, 2, (2), pp. 301-309 The Institution of Engineering and Technology 2008 